\title{
Implementing parenting programmes across cultural contexts: a perspective on the deficit narrative
}

\author{
Ruben van Esch \\ Department of Education \& Pedagogy \\ Utrecht University, the Netherlands
}

Prof. Mariëtte de Haan

Department of Education \& Pedagogy

Utrecht University, the Netherlands

\section{Authors version.}

Please cite as:

Van Esch, Ruben \& De Haan, Mariëtte (01-11-2017). Implementing Parenting Programmes Across Cultural Contexts: A Perspective on the Deficit Narrative. European Journal of Development Research, 29 (5), (pp. 983-998)

\section{Abstract}

This paper critiques universalistic 'at-risk' approaches by parenting programmes in the context of international development, arguing that local practices are neglected in research. Fifty post-training interviews with 25 participants in Western Kenya are analysed using discourse analysis. Posttraining, parents reported less physical punishment and emphasized parent-child communication more. However, the analyses show that parents see these newly introduced methods as a means to act more efficiently within the utilitarian approach to parenting they defined before training. Cultural norms related to respect, authority and compliance remained important, although attention to the responsiveness and inner motives of children had arguably started to bend and twist the older family hierarchy and the position of children in it. It is argued that the effects of such programmes in international development contexts should be considered the result of interaction between programme content and local ideas and practices. The policy implications of this dynamic are discussed.

Keywords: PARENING, VIOLENCE AGAINST CHILDREN, THE MEANING OF EVIDENCE IN INTERNATIONAL DEVELOPMENT, CULTURAL DIVERSITY, DEFICIT NARRATIVE 


\section{Introduction}

This paper critiques universalistic 'at-risk' approaches by parenting programmes in the context of international development, arguing that local practices are neglected in research. Fifty post-training interviews with 25 participants in Western Kenya are analysed using discourse analysis. Posttraining, parents reported less physical punishment and emphasized parent-child communication more. However, the analyses show that parents see these newly introduced methods as a means to act more efficiently within the utilitarian approach to parenting they defined before training.

Cultural norms related to respect, authority and compliance remained important, although attention to the responsiveness and inner motives of children had arguably started to bend and twist the older family hierarchy and the position of children in it. It is argued that the effects of such programmes in international development contexts should be considered the result of interaction between programme content and local ideas and practices. The policy implications of this dynamic are discussed.

\section{Parenting programmes addressing maltreatment?}

In an effort to protect the wellbeing of youth and prevent violence against children, parenting programmes are increasingly used as part of developmental aid efforts (Richter \& Naicker, 2013). Parenting programmes can be defined as group-based interventions aimed at changing parenting practices by 'training' and/or providing support to parents. Examples of more well-known programmes are the Australian Triple $\mathrm{P}$ and the Webster Incredible Years programme developed in the US. Parenting programmes may vary in target group, setup/design and the underlying learning theory (Cottam \& Espie, 2014) and have been implemented in many countries outside the US and Australia, such as in Iran, Thailand (Chen \& Chan, 2015) and Kenya (Vandenhoudt et al., 2010).

Most programmes are based on varying premises, including the notion that family and parent-child relationships have a pervasive influence on the psychological, physical and social wellbeing of children. Often these parenting programmes focus on removing risk factors, such as insecure attachment, harsh and inconsistent disciplining and marital conflict. In addition, they aim at increasing protective factors, such as strengthening parent-child relationships, providing a safe environment for children and providing parents with knowledge and skills to improve their flexibility and problem-solving abilities (Baker, Cook \& Borrego, 2010; Sanders, 1999; Slade, 2007).

Most programmes are set up to deal with groups, while also making use of techniques such as promoting discussion and sharing advice amongst the participants (Foolen \& Daamen, 2013), role play, watching video vignettes and giving the parents homework (Barlow, Smailagic, Huband, Roloff, 
Bennett, 2012).

Overall, scientific research has found that parenting $s$ are effective in reducing child maltreatment (Rodrigom Byrne \& Álvarez, 2011). According to effect studies, parenting programmes improve factors such as family relationships and increase parent sensitivity, reduce marital conflict, improve home safety and attachment, and decrease harsh disciplining, which in turn results in a reduction in child maltreatment (Chen \& Chan, 2016; Kaminski, Valle, Filene, \& Boyle, 2008). For example, Chen and Chan's (2015) meta-analysis of over 30 programme evaluations worldwide demonstrated that parenting programmes affect child maltreatment behaviour of parents. The analysis included research done in a diversity of Western and non-Western countries, such as Thailand and Iran, but did not include African countries. Moreover, these studies provided limited insight into precisely how these programmes work exactly, or into how the training and lessons implemented lead to the intended reduction of risk factors and improve protective factors. This is in particular the case for programmes that are implemented in settings and contexts that are removed from the context in which they were developed and tested.

Apart from an absence of process-oriented insights, studies such as these often mention that prior to the programme's implementation 'something' was not sufficient, or was lacking or wrong, and that this something was reduced after the intervention. For example, Chen and Chan (2015) concluded that, overall, parenting programmes reduce ineffective parenting, including harsh and dysfunctional parenting. According to the authors, this is due to a reduction in: inappropriate attitudes towards childrearing, abusive parenting behaviours, insufficient parenting skills, minimal knowledge about child development, and insensitivity of the participating parents. Despite the impressive scale of the analysis, the descriptions are not very informative about what terms such as 'inappropriate attitudes', 'minimal knowledge about child development', and 'faulty assumptions' actually imply. At their core, these descriptions only suggest that the parenting programmes can address a deviation from an assumed norm of appropriate and effective parenting and correct it. This leads to a conceptualization of parenting programmes as tools for eliminating inappropriate elements or addressing insufficient parental elements, emphasizing more efficient conduct and the supplementing of resources otherwise lacking. This overlooks why local practices and ideas exist in the first place and seems to simply label these elements as ineffective according to a specific standard. As such, this conceptualization lays bare a deficit narrative, in which the programmes are seen as a means to fix parenting where it is inadequate or falls short of something. When dealing with the cross-cultural implementation of parenting programmes, this deficit narrative becomes an issue based on its apparent disregard of local ideas and practices out of a need of the supposed effectiveness of the intervention, landing us in murky waters with respect to the cultural meanings 
of these changes.

This normative form of expressing effectiveness becomes especially problematic when considering Koops's (2016) argument that parenting practices and ideas are always nested in, or derived from, local ideas about personhood, childhood and parenting, and that even within our own societies the idea of what a child is and how a child should be treated, and what then can be considered as maltreatment, has changed much over time (Koops, 2016). For example, Dasberg (1975) explained that historically the idea of the child has changed, from being considered a 'little devil' that should be disciplined (sometimes harshly) to being a non-barbaric subject, to the conceptualization of the child as an innocent infant corrupted by the adult world. Ideas about parenting, identity and personhood differ across place and time and are by no means culturally and historically universal, even within our own cultures. Therefore, what are the standards for good parenting, and when does one mistreat a child?

The prospects and limits of a common framework for proper parenting: child wellbeing, neglect, attachment and the deficit narrative

Generally, the Convention on the Rights of the Child (CRC) (UN, 1989) is seen as the political basis for a common, and presumed universal, framework against child maltreatment or violence against children. Globally, the CRC is considered the norm, as a total of 192 countries worldwide have ratified it, making it an accepted standard amongst these nations regarding the definition of violence against children. Derived from the CRC, the concept of child neglect is used by scholars as a means to measure and describe how children are treated by caregivers (Pollard \& Lee, 2003). However, the CRC is conceptually broad, and more specific standards are required to determine how children should be parented.

A more concrete way to label proper parenting versus improper parenting is through the use of the concept of neglect. Neglect has been labelled the 'most common and frequently fatal form of child maltreatment' (Proctor \& Dubowitz, 2014). Although there are many different definitions of neglect, it can be summarized as 'the persistent failure to meet a child's physical and/or psychological needs likely to result in the serious impairment of the child's health or development. A child carer is neglectful when he/she fails to provide adequate food, shelter and clothing, failing to protect a child from danger, or the failure to access appropriate medical care or treatment' (Dubowitz, Black \& Starr, 1993). Although neglect is commonly perceived as something that occurs without the intention of the carer, it also includes the latter's unresponsiveness to a child's basic needs. Neglect is often directly related to the idea of wellbeing, in the sense that the absence of 
certain conditions (both physical and emotional) are seen as endangering child wellbeing (Dubowitz, Black \& Starr, 1993; Tanner \& Turney, 2003).

However, the use of the term neglect is problematic. The reason for this is because it also reinforces a deficit narrative, in which particular practices that endanger perceived child wellbeing are considered to be based on shortcomings, both those of the wider social context, as well as those of the respective carers. For example, in terms of the definition of neglect as the denial of a certain level of health care to the child, strict adherence to this norm or principle would imply that mothers living in a remote rural area might be considered neglectful if they do not provide their child with access modern medicine, implying their parenting practice is insufficient. Here, it is argued that the use of such concepts may be inapplicable in international practice. We believe that the term neglect may disqualify parents who have limited resources, knowledge and skills from being considered proper caregivers because they do not meet the respective norms. These standards pertaining to neglect and child wellbeing are unrealistic and even unjustified. This issue of standardization is an especially relevant point for developmental aid practices, as resources are often limited within the areas where such aid is implemented. Parents who do not have access to these resources are in danger of falling into a category of people who, by default, are considered insufficiently equipped to be good parents under those circumstances. In other words, adherence to this standard would render a large percentage of parents around the world as 'bad' parents by default. In this case, we see the deficit narrative placing an emphasis on what parents cannot do, and do not have, rather than examining the effective parenting practices within the respective social and environmental context.

In addition to using concepts that paint certain parenting practices as deviant by definition and the result of economic factors, these normative underlying concepts may also disregard cultural practices of non-Western communities. Probably the most discussed example of the denial of alternative cultural norms evolves around the use of attachment theory in an international context. Keller (2015) provided a multi-level description of the complexity of generalizing attachment theory beyond the Western context. Despite attachment being widely accepted and extensively studied as a social scientific construct, there is a relatively small cross-cultural database with respect to attachment outside the Western context (Ijzendoorn \& Sagi-Schwartz, 2008). In addition to the theory's inherent notion that a child is an independent agent (which is not a universally accepted premise) (Keller, 2015), attachment theory also emphasizes single caregivers. More specifically, the theory focuses on a dedicated mother-child interaction that is considered beneficial to proper attachment. As with neglect, the inability to provide such single-parent/mother care implies a threat to child wellbeing, namely its attachment, in communities where shared parenting is the norm or 
where parents primarily engage with their children without elaborate and direct one-to-one interactions.

In summary, we consider that finding an applicable and justifiable conceptualization of what constitutes proper parenting is extremely complicated when taking into account contextual factors. We must be critical of what constitutes interculturally valid constructs to determine and measure what good parenting is, what the child needs, and what a parent can provide in different contexts. The deficit narrative illustrated above blinds us not only to local ideas and practices when working from mono-cultural constructs, but also to how ideas and practices interact with the parenting programmes implemented. Therefore, the narrative has an impact on our attempts to determine how these programmes work and what their effects are. This paper hopes to address this oversight, without suggesting that our approach can resolve the dilemmas sketched above once and for all. Our goal is to advance the critical questions and the discussion, and gain more insight into how local practices and beliefs impact on interventions 'from outside' by presenting material from an evaluation study based on an ethnographical approach in Kenya.

\section{A case study: evaluating skilful parenting in Kenya}

Based on the considerations mentioned above, we present our analyses in an effort to understand how parenting programmes affect local parenting, and how newly introduced ideas and practices relate to the presiding concepts of parenting. As part of the analysis, we will investigate whether parenting programmes can reduce violence against children. We use data from an evaluation study done in 2014 of the Skilful Parenting programme developed by the NGO ICS, carried out in Western Kenya (van Esch \& de Haan, 2016). In the following section, the Skilful Parenting programme will be briefly discussed, followed by the methodology used in the evaluation. Its suitability as a case study for this paper is derived from the fact that it is a study of a parenting programme, based on Western ideas, that was adapted to a local context, with a special interest in reducing violence against children. For this paper, our analysis will take into account the elements introduced by the programme that relate to the improvement of child wellbeing. A more complete overview of our evaluation study can be found in Van Esch and de Haan (2016). In addition, in our analyses we will explore how these new parenting elements relate to presiding ideas and practices, and ask why they were adopted.

\section{Skilful parenting in Kenya}


The Skilful Parenting programme was implemented to address a variety of social issues, including violence against children in Western Kenya. Many families in Kenya are exposed to factors that make childrearing extremely challenging, as over half of Kenya's population lives beneath the absolute poverty line. Poverty is still on the rise due to inflation, a shortfall in agricultural production and constant climatic issues, such as floods and droughts, which cause problems for many Kenyans. The infant mortality rate in Kenya was 79 in 1,000 in 2003, with a rate of 95.8 for the poorest 20 percent of the country's population (Wilson \& Ngige, 2005). Many families in the rural areas of Western Kenya are exposed to certain levels of social or physical aggression and domestic violence throughout their lives (Mburugu, 2005; Wilson \& Ngige, 2005). A report regarding violence against children in Kenya from 2010 stated that almost two thirds of the respondents had experienced physical violence before the age of 18 , ranging from being slapped, pushed, punched and kicked to being whipped or beaten with an object (UNICEF, 2010), while the use of physical methods to discipline children is common practice for most parents (Akinyi, Fiti \& Lasser, 2013).

In collaboration with local partners, ICS Creating Change developed and implemented the Skilful Parenting programme in rural areas of Western Kenya. The goal of the programme is to work with parents to strengthen their parenting role, aiming to prevent and reduce child abuse, neglect and family disintegration, amongst other goals. The programme is part of a larger initiative for socioeconomic improvement in the area, where the parenting programme's aims include attempting to reduce child abuse in Western Kenya. The programme is based on the idea of 'civic-driven change', which assumes that social change must or will happen as a result of 'civic agency' (Fowler \& Biekart, 2011).

The Skilful Parenting programme contains five modules dealing with the topics of family relationships, parental roles and responsibilities, self-care \& self-esteem, values \& discipline and communication. Each group of participants ideally consists of 18-24 people (ICS, 2012). Considering the different types of parenting programmes mentioned above, the Skilful Parenting (SP) programme contains strong relationship-based elements, such as family dynamics and effective communication.

The programme's central concepts were reviewed for cultural sensitivity; for example, whether they took into account a more collective notion of family, including involvement of grandparents, and the siblings and in-laws of the parents, and adhering to particular norms on the expression of affection within the family. The programme also adheres to local social conventions of presenting and discussing issues, such as using songs, biblical references and forms of presenting and speaking that are directed to more collective sharing of knowledge in a communal way. In addition to these adaptations, the programme adheres to international scientific ideas and concepts 
associated with relationship-based parenting programmes (such as the importance of attachment, positive reinforcement and consistent parenting behaviour), and introduces other international elements of parenting such as Baumrind's parenting styles (Levin, 2011). In summary, the programme was developed to respect the culture and the local habits of the parents and at the same time to share Western-oriented knowledge and skills (Ogutu, 2015).

\section{Methodology}

For this paper, we focus on a few specific elements of our evaluation research related to family relationships, with an emphasis on the relationship and communication between parents and children. The evaluation study examined existing parenting ideas and practices, as well as how the programme possibly changed these practices and ideas.

Our analysis considered how parents view the role of children as it pertains to their own role as a parent, followed by inquiries about how these concepts relate to their view and understanding of parenting overall. We explored what parents want for themselves and their children, and how they act to achieve these goals. With respect to how parenting changes during and after programme participation, we discussed parenting ideas and practices such as how the children are disciplined and how this can be placed in the context of the parents' view of child wellbeing, comparing these before and after the intervention. Perhaps most importantly, rather than only focusing on what may have changed, we also focused on why parents adopted these new ideas and practices in particular, based on their own observations.

As part of the evaluation, a pre-post-test design was used involving parents and other caregivers who had participated with the ICS programme in Kenya. The effects of the intervention were inferred from a parenting survey that measured (self-identified) competences prior to and after the intervention. This design was combined with a process-based approach, where two full programme sessions were observed over time. Two rounds of in-depth post-training interviews and ethnographic observations were also carried out with smaller samples. In this paper, the qualitative data from the in-depth interviews will be used.

For the in-depth interviews, we took a stratified sample of 30 respondents from the larger sample of 90 parents. Respondents in the larger sample were recruited from the two main areas of Busia and Kakamega, divided into five smaller areas of Shibuye, Shidodo, Namalenga, Amungura and Olepito. Each of the five locations had one group of local parents who participated in the programme, and at least 20 participants from each group were selected for the research. During sample selection the languages spoken were also taken into account, with respondents required to 
have minimum skills in spoken Kiswahili. The selection of caregivers ensured they were representative of the target group for ICS. This implied that parents had to be local residents from rural communities. Background factors that were taken into account were equal representations of gender, schooling level, age, family size, carer role and, if relevant, ethnicity (tribe).

The sample of 30 parents to be interviewed was drawn from those who participated in the above-mentioned survey, taking into account equal representation of the above-mentioned characteristics. A higher women-to-men ratio was representative of the total observed participants of the programme. Ethnicity was generally homogenous across the five groups, making equal numeral representation from these groups sufficient for tribal representation. All participants were interviewed twice, once immediately after participating in the programme, and once several months afterwards (3 to 4). During the second interview, a total of 25 parents were interviewed due to dropout.

Interviews were held in Kiswahili or English, depending on the respondent's preference, by the first author and a translator who spoke both English and Kiswahili and were translated from and into English on site. The translator was recruited from the area and was familiar but uninvolved with the communities of the respondents. For practical reasons, the English transcriptions will be presented in this report. The interviews were all audiotaped and transcribed by local research assistants.

The inclusion of process-based method design strengthens the pre-/post-test setup through cross-verification of the potential impacts of the intervention. In addition, this methodology provides insight into the specific socio-cultural contexts in which the parents and caregivers find themselves based on their own perceptions, and functions to describe the impact of the programme in terms of qualitative change in situ and over time, respectively.

Instruments and analyses: definitions of parenting, family relationships, development and training concepts

We paid specific attention to what changed and what did not, and how local customs and traditions were positioned against newly adopted ideas and practices. We made use of interpretative interview analysis methodologies, primarily borrowing from discourse analysis (Kvale, 1996; Gee, 2014).

The interviews were semi-structured and consisted of four sections with individual themes. The first part of the first interview explored the perceived meaning of parenting held by the respondents. This section aimed to gain insight into what parents believed the local standards for good parenting to be, what specific goals the parents had for their children, and how they aimed to achieve these goals before the training programme. This provided the bases for further inquiry. As 
part of the first part, parents were also asked whether they had experienced changes in their parenting practices and/or ideas over the past months, and whether these changes related to the programme.

The second part concerned family relationships and contained questions that focused on the roles of specific family members based on age and gender, and on how members of the family related and communicated with one another. The third part concerned development, focusing on how parents initially learned and developed their skills and practices as parents, and if and how that development related to the lessons they learned from the programme. The fourth part was aimed at determining how parents experienced the specific process and content of the programme, as well as giving parents an opportunity to voice their personal views and preferences on these topics.

\section{Analysis and Results}

\section{$\underline{\text { Reflections on beliefs and practices before participation }}$}

When asked what they thought a good parent was almost all of the respondents' answers illustrate that at the start of the programme they primarily viewed parenting in terms of providing children with food and education. When asked about the role of a parent within the family, one mother stated:

[...] a good parent is a parent who takes good care of the children and provides [for] the needs of the children like educating the children, feeding the children, looking at the health of the children, if they are sick they are taken to the hospital and also educating the children.

F, 39

This parent sees proper parenting practice as providing for the needs of children. The focus seems to be on providing food and access to medical services. When asked about what a good parent should do, parents stated that they wanted to be competent in, or even improve, their farming skills, increase their income or ensure their children had food or could go to school. Please note that parents are often referred to as he/she by the translator, as in the excerpt below.

[...] she (translator refers to parent) has to work hard [...], she has five children and there's one of her daughters who sat for exams and she has to till her farm, plant maize and take maize and go sell so that she can get money to go and educate her children.

F, 39 
There is an emphasis on managing financial needs and environmental factors surrounding the child that also fall under the responsibility of the parent. This 'economic' or utilitarian perspective was prevalent amongst the participants, even if it was often expressed differently by individual parents, who also referred to access to 'hospital', 'medication', 'clothes' and 'books' as the means that they should provide to their children and the family.

As can be seen in the excerpts above, parents often mention education. When asked about this, parents stated that the importance of education derives from the idea that an educated child will find a job and make money. In response to this, parents were asked what kind of job they would like their children to have. They reported that they would like their child to be a doctor, manager or teacher, referring to professional positions within their communities that enjoy a higher socioeconomic status in both in terms of wealth and respect.

After mentioning these professions, the parents were asked why these were important. They reported that they wanted their children to be educated and find a job so they could support them one day. In general, parents referred to this particular benefit of their children's education more than they did to the benefits of education to the children themselves.

\section{[...] now that she is educating the children she wants them to complete their education, get jobs and support her. \\ F, 37}

The reason why this particular emphasis seems relevant is because parents show little consideration for the experiences of the child specifically. Generally, the child's education is initially seen as relevant to the parent.

According to these findings, the role of a parent was most commonly defined as being able to provide resources as a way to ensure the physical wellbeing of the children and to send them to school. In addition to the physical aspect, a child's 'wellbeing' seems most often to refer to their economic and social status, while the parents referred little to the emotional and psychological domains. Parents did place emphasis on the schooling of their children. The main reason for this was to ensure that the child acquires a decent level of wealth and social status, illustrating that parents have specific aspirations regarding the resources a child will gain access to as an adult, and that they also have the child's economic wellbeing in mind.

In response to being asked about the roles of children in the family, parents reported that children contribute to working in and around the house, as well as on the farm. 
She's saying that the children have their roles like for the girls they have to clean the house, the boys need to go and slash the compound and take care of the cattle.

F, 39

When asked about the responsibilities of children at a certain age, the parents said they expected their children to take care of them later in life, the same way they themselves had taken care or still takes care of their own parents. Investing in the education of a child may result in a better chance of being supported, as the child may have more resources to provide for the parents in the future.

In addition to the more practical contributions to the household, and as well as being a future caregiver, it was also reported that the child's role was to respect their elders and adhere to certain norms, such as being obedient to their parents.

$[. .$.$] like respecting the elders [...] when they are sent somewhere they are supposed to go.$

F, 39

Children are also expected to exhibit proper behaviour towards the elders outside the household. It seems to be generally perceived that children should show a sense of subordination to their elders, and do as they are asked.

So she's saying that the role of a child is to respect the parents and also to do all the tasks that the parent wants them to do.

F, 45

The fact that obedience and respect of the child are emphasized, in particular with respect to age within the family, points to a hierarchical social and family structure, in which parents hold firm authority over the child.

With respect to how parents strive to ensure their children achieve the parents' desired goals about their children, respondents did not automatically mention specific socialization practices or teaching their children the virtues mentioned. During the interviews, the issue of how 'proper' child conduct was ensured was brought up. The parents explained that children learn how to behave through storytelling and education involving cautionary tales, in which the grandparents especially played an important role. 
They could just sit with the kids maybe in the evening, may be after supper they all gather. The grandmother or the grandfather now begins to talk with those children. Like me, our grandmother lived for long, so every evening we could all gather in one house and she could really teach us on how to live. When you get married what happens, when you get a kid what you should do. How to cook, how to be clean.

$\mathrm{F}, 52$

As the example shows, part of the task of socialization was reported to have primarily been undertaken by the grandparents in the past, rather than the actual biological parents. Grandparents are remembered as advising their children and instructing them on 'how to live' and how to prepare for adult life. The respondent of the prior example also stated:

[...] we used to stay with our grandparents and actually they used to educate us much more about how to live, even better than our parents.

$F, 52$

Generally speaking, respondents would make a distinction between the specific roles of parents and grandparents in bringing up children when they talked about 'how things were'. In general, parents valued the more extended family structure of the past, in particular with respect to the role of grandparents, which also implied a criticism of the current value of parental social roles. Other interviews revealed that the parents trained the children in tasks and skills, while the grandparents were perceived as the mentors providing moral and social guidance. It was explained that this family structure was less prevalent in the current lives of parents.

In response to the question of how they personally communicated with their children, parents explained that it was mostly directive, telling the children what to do. Children would learn specific tasks primarily through observation, and when told to do a specific task the children were expected to learn or do that task without much instruction. These tasks were different for boys and girls, where men were expected to work in the fields, and women to clean and cook. The parents stated that children who failed to do as they were told would be punished, varying from verbal to physical punishment, including methods of scolding, caning or depriving them of food. The following example illustrates this, while also making clear that disciplining was not so much a task of the nuclear family but of the community. 
Like I find a kid playing on the road or a kid has hit another kid [...] traditionally, I just had the right of taking a stick and caning the kid. You see?

$\mathrm{M}, 34$

In summary, the parents defined their role in a utilitarian sense and placed an emphasis on providing access to resources and care. Parents are the carers who provide the right circumstances for their children to develop. Parents want their children to become people who adhere to local hierarchical norms that are befitting to their status as children, such as showing respect to their elders and being compliant. In addition, parents aspired for their children to gain status and wealth. When asked how the children are socialized to adopt this proper behaviour, the parents referred to the use of storytelling and the traditional role of grandparents that was no longer prevalent. Correction and discipline was done through verbal and physical punishment.

\section{Reflections on roles after participation}

Parents were asked to review their ideas and practices in relation to parenting after completing the training programme. Initially, they were asked whether they had experienced changes in their parenting. Once parents had freely reflected on the perceived changes, they were asked whether the programme had changed the way they see their role as a parent and the role of their children. Subsequently, we asked them to explain what had changed in particular, how it had changed and why. They were also invited to reflect on how their ideas and practices had possibly changed, whether the changes were for the better or not, how the ideas inherent to the training programme deviated from their own original ideas and how they personally felt about the changes.

It should be noted that parents often had a difficult time reflecting on their ideas and attitudes and describing any changes. Most parents found it easy to explain how one should behave and even how they behaved themselves, but to identify the underlying ideas and values explaining why such behaviour occurred or why it was preferable was a challenge. This was overcome by asking parents how they personally felt about specific behaviour, and then why the behaviour was or was not preferable to other behaviours. This often led the parents to explore their own interests and values.

As a first step, the participants were asked what they perceived a good parent to be after completing the training programme. An emphasis on providing food, clothing, shelter and education for their children remained prevalent amongst all parents. When one mother was asked about a parent's roles and responsibilities in the family, she responded: 
Taking care of the family as a parent she has to make sure that the children get food, the children get education and also they get somewhere to sleep.

F, 39

In response to the same question, another mother stated:

If the child comes back from school she has to know about what he/she needs from school and she meets the needs of the child and also if the child comes back home from school she needs to give them food so that they feel that they have a good parent.

F, 20

This respondent placed emphasis on knowing the needs of her child, including providing food.

The role of children was also discussed. Most of the parents maintained the same perceptions they, had prior to the training programme. To the question: 'What is the role of your child in the family?', one mother responded:

[...] she wants her children to be obedient, she wants the children to know God, she wants them to go to school and have a good future and also she wants her children to be - what she meant with a good child, a good child is a child when she is talking to them they don't respond in a bad way.

$\mathrm{F}, 38$

Here, we again see the focus on obedience, obtaining an education and having a prosperous future. Religious piety is also deemed relevant. Contributing to the household is still considered a child's responsibility, as the following example shows:

[...] So the role of a child at home when he/she is back home from school is to fetch water, help in washing and help in cleaning the compound.

$F, 53$

Showing respect to and compliance with parents and elders remained important, as one mother commented below: 
[...] children need to be disciplined and also they need to obey everything that the parents tell them.

$\mathrm{M}, 44$

In addition to these similarities, almost all of the respondents also shared views that were different from those from before the training. With regard to parental roles, one mother stated:

[...] a good parent is a parent who is an example to the children and also she is a parent who hears what the children say and also get to tell them the things that they are supposed to be doing.

$-$

In this excerpt we can see that being a role model and communicating and listening to the child is now included in the role of a parent. This new emphasis on communication was widespread amongst the respondents. Almost half mentioned an alternative way of interacting with their child on their own initiative, and all mentioned changes when asked directly. When asked how communication with her children had changed, one mother said:

So she's saying that now that she has been taught she's able to know how to treat the children, how to hear what the children want and in that way when she's able to hear what the children want from her. The children hear what she wants from them. The relationship between her and the children is good.

F, 36

Interestingly, apart from the emphasis on communication, there was also recognition of children being able to determine their needs and voice their interests, as well as a reflection on the relationship beyond established role patterns. There was a level of awareness about the experiences of the child that was not touched upon by parents when reflecting on practices used before the training programme.

This recognition of the child's experiences led parents to reflect on how they could more effectively direct their children through communication. When asked if the changes in communication had affected her or her children, one mother said:

[...] talking to the children is good because when you talk to them you are able to tell them when they have done a mistake and they improve.

F, 36 
Other parents also mentioned the benefit of listening to children. The changes mentioned suggest two shifts in the way the parents related to their children. Firstly, this parent's answer reflects a vision of how her interaction shapes the behaviour of her child, which was not expressed in the interviews that reflected on practices used before the programme. This can also be said in regard to being a role model as a parent. Secondly, parents were more inclusive of the experiences of their children. They attributed relevance to their children's input in conversations and mentioned that the change in the way they talked with their children had improved their relationship.

In addition to these changes, one of the most common answers in relation to communication was that respondents said that before the programme they would kiboko (cane) the children when they made a mistake, but now, after participating in the programme, they did so less often. For example, when asked if communication with her children had changed, one older mother said:

One thing that has made me happy, in the past when my child makes a mistake, I would beat them with anger but after the training I was advised not to beat my children when I am bitter because I can end up killing the child. Instead, I should talk to the child, which I see is working very well.

F, 60

Here, we see a shift away from beating a child out of frustration, towards a reasoned response and the use of dialogue. The shift in communication is related to an emphasis on having dialogues with children, as mentioned above. Parents are more prepared to 'sit down with their children', rather than using physical punishment. Thus, parents use the alternative methods of communicating, which they also find to be successful in redirecting their children's behaviour. A few parents mentioned that they still might resort to physically disciplining their children if they were insubordinate, but preferred talking.

Because engaging children in dialogue was not perceived as the common way of doing things before the training programme, parents were asked to reflect on the possible benefits of these alternative methods of communicating.

He is now not harsh to the children and even the children have begun to come close to him because at times the children will fear coming near to him because they knew he was going to hit them.

$\mathrm{M}, 44$ 
The example above describes a father who perceived his children to be more vocal and less inhibited about expressing their desires and needs, such as what they required for school. These changes enabled parents to ensure children had what they needed in relation to food and school fees and as such they experienced more control over their children's lives. Based on the responses, the upside of this new form of communication and the apparent shift in the way the children perceived their parents was primarily linked to this enhanced sense of control over their children.

In addition, before the training programme, the parents held the child's compliance and adherence to the family hierarchy in high regard. This had not changed. In fact, after the programme, parents found their children to be more compliant when communicating with them differently. Ironically, it appears that the more democratic and inclusive way of communicating taught by the parenting programme reinforced the parents' original ideas about hierarchical family structures. Moreover, the parents believed that using a more inclusive manner of communicating with the children resulted in a more 'peaceful' household with less conflict. These relationships were also reported to be enjoyed because of the lower levels of friction and stress in the family.

Regardless of the improvements experienced, a fair number of parents remained critical of their own abilities even after the training programme. They stated that they were trying but could not properly cover all the responsibilities of a parent they themselves found important. In response to the question: 'Do you feel like a good parent?', one mother replied:

She is a better parent [but] she is not a very good parent because when the children are sent home for school fees she is not able to pay for the school fees so she feels she is not really meeting the needs of the children.

$\mathrm{F}, 55$

This excerpt illustrates that parents still feel they have some way to go when it comes to improving their practices. Moreover, the ideas about what roles and responsibilities a parent has, as reported when reflecting on practices before the training programme, were still deemed determinants for being a good parent after the programme. Although parents emphasized changes in communication after the programme, it appears that original norms grounded in the provision of material resources that support and mediate child development remained important elements in defining who is, and who is not, a good parent.

To summarize, parents report both similarities and differences in relation to the role of parents and the role of children after participation in the training programme. Afterwards, parents still defined themselves as those who provide the right circumstances for their children to develop. Parenting competence continued to be primarily measured on the basis of a utilitarian model of 
parenting. In addition, children continued to be seen as needing to be compliant and respectful of the hierarchical structure, and adherence to this structure remained important.

Reflecting on practices used after the training programme, parents appear to consistently place much greater emphasis on how they communicate and exhibit more awareness of their children's own experiences. The use of physical discipline has reportedly been reduced, and parents preferred to verbally correct their children, as it improved their sense of control. Parents reported that they talked openly with their children about what they want, and what the children want. An improved understanding helped the parents attend to the child's needs, which is perceived as equivalent to being a better parent. The democratic practice of talking to children is seen as an effective way of controlling them, and the child is seen to be more receptive to the parent. Interestingly enough, according to the parents, this made the children more inclined to comply with the parents' requests, in accordance with the original hierarchical family structure.

\section{Discussion}

We started this paper by formulating a critique regarding a deficit narrative in evaluation research, arguing that this is based on a mono-cultural perspective on parenting. We argued that this perspective may unknowingly colour both our perceptions of how parenting should be changed through intervention programmes, and how these parenting programmes actually influence the participants. Data analysis was used to sketch an image of how parenting changed after participation in a parenting training programme based on Western notions of parenting, and how these changes related to existing local ideas and practices of parenting. Here, we will briefly discuss the case study results and attempt to illustrate how the changes and processes might be labelled within a deficit narrative as defined in this paper. Subsequently, we will reflect on how this narrative skews our perceptions, making a case for a different approach.

The case study results showed that the parents' perceptions of their own roles and responsibilities, as well as those of their children, changed. However, we also found that many existing ideas and norms remained. Thus, there was both change amongst parents and continued adherence to local conceptions of good parenting. One of the primary changes reported concerned the way the parents interacted with their children. This change was connected to a greater focus on the part of the parent on what their child was experiencing. Parents talked with their children and listened to them in an effort to allow their children to state their needs. Moreover, rather than resorting to corporal punishment and caning, parents declared that they now talked more to their children and directed them verbally. In addition to the changes that the parents associated with the 
programme, they also mentioned changes in parenting practices within the community, which they saw to be independent of programme influences. For example, where grandparents were once relevant participants in child socialization, they are now considered to be less involved.

When one looks at these effects from within a deficit narrative as we described above, it could be stated that the programme reduced ineffective and wrong parenting practices such as caning, and that parents adopted the more efficient form of verbally correcting their offspring. In such a framework, it would be argued that parents gained knowledge about the relevance of the experiences of the child, and that a more child-inclusive and democratic form of communication was adopted by the parents, replacing ignorant positions and assumptions. Parents were listening more and were more aware of the child's experiences after the programme. In short, they were now using practices that were more respectful and protective of the physical, social and psychological wellbeing of their children in comparison to the harsh punishment practices of Kenyan parents.

However, as the results showed, the programme expanded on the already existing norms of parenting, and the newly introduced tools that were provided helped parents to act more efficiently within the cultural model of parenting they had before the programme. In this model, respect and compliance remained important elements, as did the dominance of a utilitarian approach to parenting, even if it might be argued that the greater attention and responsiveness to their children and their inner motives had started to bend and twist the old family hierarchy and the position of children in it.

These changes imply at least a partial win from the perspective of the effect of the parenting training, in the sense that certain parenting behaviour was replaced by more 'effective' or 'democratic' practices, depending on the perspective adopted, which improved the care and safety of the children. Physical punishment was also reduced. However, the strong hierarchical nature of the family structure and the roles of both parent and child remained the same. The extent to which we can speak of a hybrid or integrated form of Western and Kenyan parenting is unclear. This should be further researched. Nevertheless, we argue that without a proper understanding of local ideas and how the programme's content relates to them, evaluating programme effects from within the deficit narrative may blind us to what has truly changed and what has not, and most importantly what these changes mean.

Despite the above-mentioned issues, we think it is crucial to keep in mind the importance of the underlying aims of preventing violence against children. Ultimately, there is a desire to protect children and their right to live healthy and fulfilling lives. In this respect, although we emphasized the need to understand different cultural concepts of parenting, we are aware that descending into absolute relativity (moral and cultural) cannot and should not be done. 
Having said this, we feel that both policymakers and evaluators should strive to have a proper and thorough understanding of local ideas about and practices of parenting before implementing new ideas or practices. More resources should be invested in qualitative research aimed at looking at local individual parenting practices, in addition to paying attention to quantitative measures, such as the prevalence of children who are maltreated. Local values and norms should be mapped and used to consider what should be changed or influenced. They might also serve as a base measurement in determining how the programmes implemented affect the participants' ideas. It should also be investigated what possibilities for change within these respective contexts already exist aside from interventions. In addition, process-oriented observations and other tools designed to measure processes of change should be used to better understand the mechanisms behind programme effects. This recommendation is particularly relevant, as this will reveal how local community members learn, and it will provide insight into how well suited the programmes are for upscaling and implementation outside their observed context. 


\section{References}

Akinyi Wadende, P., Fite, K., \& Lasser, J. (2013). The Kenyan Parent in Changing Times. In Selin, H. (2013). Parenting Across Cultures: Childrearing, Motherhood and Fatherhood in Non-Western Cultures. Springer, New York.

Baker, C. H., Cook, K. L., \& Borrego, J. (2010). Addressing cultural variables in parent training programs with Latino families. Cognitive and Behavioral Practices, 17, 157-166.

Barlow, J., Smailagic, N., Huband, N., Roloff, V., Bennett, C. (2012). Group-based parent training programmes for improving parental psychosocial health. Campbell Systematic Reviews.

Bunting, L. (2004) Parenting programmes: The best available evidence. Child Care in Practice, 10, 327-343.

Chen, M. \& Chan, K. L. (2016). Effects of Parenting Programs on Child Maltreatment Prevention: A Meta-Analysis. Trauma, violence, \& abuse, $17,88-104$

Cottam, S. \& Espie, J. (2014) Discourses Underpinning Parenting Training Programmes: Positioning and Power. Children \& Society, 28, 465-477.

Dasberg, L. (1975). Grootbrengen door kleinhouden als historisch verschijnsel. Amsterdam, Boom.

Dubowitz, H., Black, M., \& Starr R. H. (1993). A conceptual definition of child neglect. Criminal Justice and Behavior, 20, 8-26.

Dubowitz, H., Feigelman, S., Lane, W., \& Kim, J. (2009). Pediatric primary care to help prevent child maltreatment: The safe environment for every kid (SEEK) model. Pediatrics, 123, 858-867.

Esch, van, R. P. \& de Haan, M. (2016). Learning under the tree: An evaluation of the skillful parenting program in West Kenya ICS. Retrieved from ICS Website: http://icsafrica-sp.org/mediaupload/DOWNLOADS/Learning\%20under\%20the\%20Tree\%20Evaluation\%20of\%20SkillfulPar entingWestKenya.pdf

Foolen, N. \& Daamen, W. (2013). Wat werkt bij oudertrainingen? Nederlands Jeugd Instituut.

Fowler, A. \& Biekart, K. (2011) Civic driven change: a narrative to bring politics back into civil society discourse. Working Paper No. 529, ISS, The Hague.

Gee, J. P. (2014). An introduction to discourse analysis: Theory and method. New York, Routledge. ICS (2012). Skillful and conscious parents facilitators guide. Retrieved from www.icsafrica.org Kaminski, J. W., Valle, L. A., Filene, J. H., \& Boyle, C. L. (2008). A meta-analytic review of components associated with parent training program effectiveness. Journal of Abnormal Child Psychology, 36, 567-589.

Keller, H. (2016) Attachment. A pancultural need but a cultural construct. Current Opinion in Psychology, 8, 59-63. 
Koops, W. (2012). Infantilization, civilization, and child abuse. European Journal of Developmental Psychology, 9, 11-20.

Kvale, S. (1996). Interviews: An introduction to qualitative research interviewing. London, SAGE. Levin, E. (2011). Baumrind's Parenting Styles. In Goldstein, S., Naglieri, J. A. Encyclopedia of Child Behavior and Development. New York, Springer.

Mesman J., Van ljzendoorn, M. H., \& Sagi-Schwartz, A. (2008). Cross-cultural patterns of attachment: Universal and contextual dimensions. In J. Cassidy \& P. R. Shaver (Eds.). Handbook of attachment: theory, research, and clinical applications (190-815). New York, NY: The Guilford Press.

Mburugu, E. K., \& Adam, B. N. (2005) Families in Kenya, in Adams B. N., \& Trost, J. Handbook of World Families. New Dehli, SAGE Publications.

Moore, K. A. (1997). Criteria and indicators of child well-being. In Hauser, R. M., Brown, B. V., \& Prosser, W. R. Indicators of Children's Well-being. New York, Russel Sage Foundation.

Ogutu, B. (2015, February 22). personal communication.

Pollard, E. L. \& Lee, P. D. (2003). Cold well-being: A systematic review of the literature. Social Indicators Research, 61, 59-78.

Proctor, L. J. \& Dubowitz, H. (2014). Child neglect: Challenges and controversies. In Korbin, J. E. \& Krugman, R. D. Handbook of Child Maltreatment. New York, Springer.

Richardson J. \& Joughin C. (2002). Parent-training programmes for the management of young children with conduct disorders: findings and research. Gaskell.

Richter, L. M., \& Naicker, S. (2013). A Review of Published Literature on Supporting and Strengthening Child-Caregiver Relationships (Parenting). Arlington, Virginia: USAID's AIDS Support and Technical Assistance Resources, AIDSTAR-One, Task Order 1.

Rodrigo, M. J., Byrne, S., \& Álvarez, M. (2012). Preventing child maltreatment through parenting programmes implemented at the local social services level. European Journal of Developmental Psychology, 9, 89-103.

Sanders, M. R. (1999). Triple P-positive parenting program: Towards an empirically validated multilevel parenting and family support strategy for the prevention of behavior and emotional problems in children. Clinical Child and Family Psychology Review, 2, 71-91.

Slade, A. (2007). Reflective parenting programs: Theory and development. Psychoanalytic Inquiry, 26, 640-657.

Tanner, K. \& Turney, D. (2003). What do we know about child neglect? A critical review of the literature and its application to social work practice. Child and Family Social Work, 8, 25-34. UN General Assembly resolution 44/25, Convention on the rights of the child adopted and opened for 
signature, ratification and accession (20 November 1989) available from ohchr.org/Documents/Professionallnterest/crc.pdf

Unicef (2010). Violence against children in Kenya: Findings from a national survey. Retrieved from https://www.unicef.org/esaro/VAC_in_Kenya.pdf

Vandenhoudt, H., Miller, K. S., Ochura, J., Wyckoff, S. C., Obong'o, C. O., Otwoma, N. J., Buvé, A. (2010). Evaluation of a U.S. evidence-based parenting intervention in rural western Kenya: From Parents Matter! to Families Matter! AIDS Education and Prevention, 22, 328-343. 